\title{
"||||||||||||||||||||||||||||||||||||||||||||||||||||||||||||||||||||||.
}

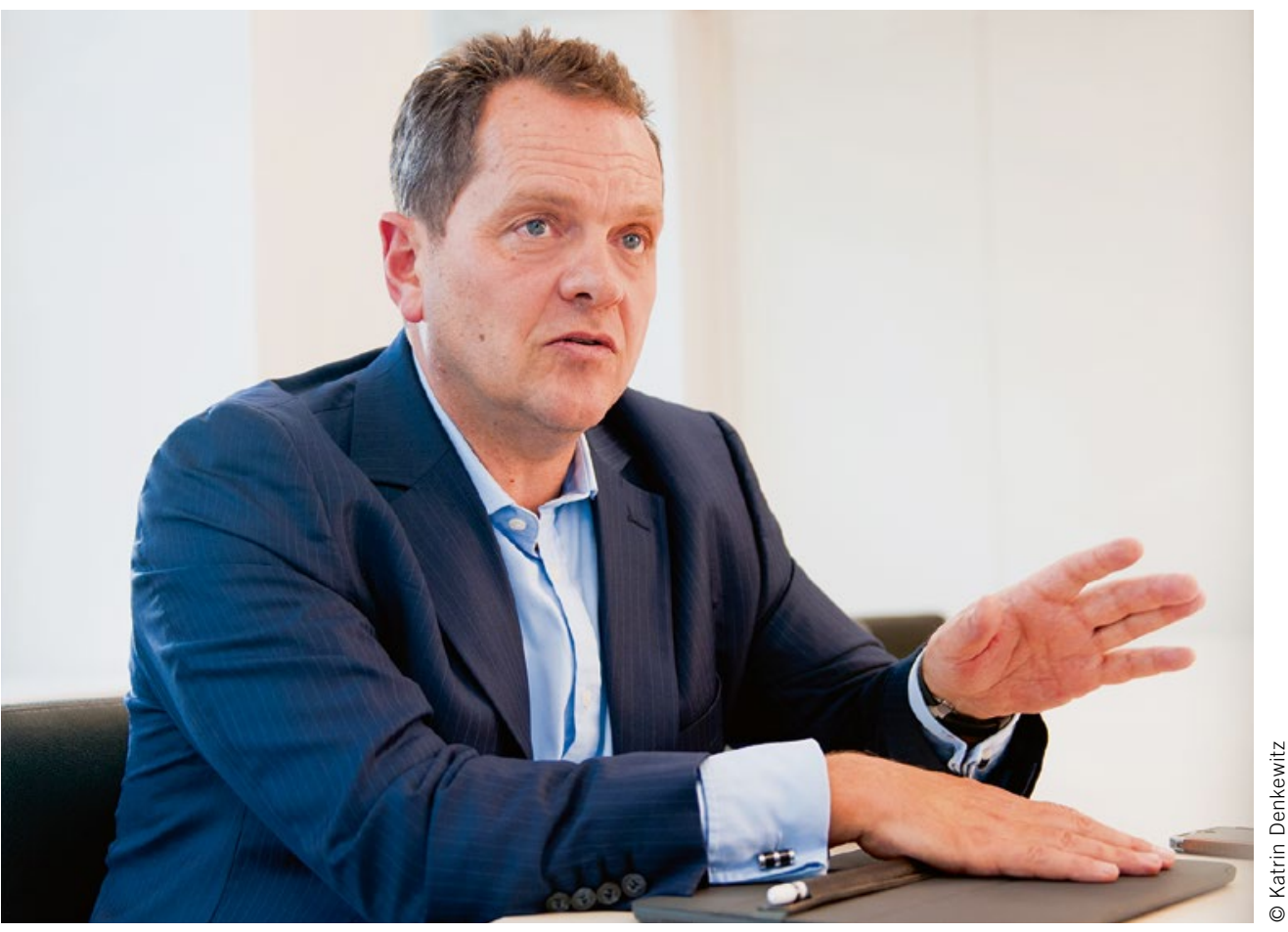

Dr. Wolfgang Bernhart Partner des Automotive Competence Center von Roland Berger

\section{Mehr Schlagkraft im Paradigmenwechsel}

Der klassische SOP ist passé. Denn das vernetzte Fahrzeug wird zum Teil des Internets der Dinge, das auch nach Verkauf aktuell gehalten werden muss. Die heutige E/E-Architektur, in der eine Vielzahl von Steuergeräten über die sogenannte K-Matrix kommuniziert, ist hierfür allerdings zu unflexibel, die resultierende Komplexität wird zunehmend unbeherrschbar.

Der Lösungsansatz ist bekannt: Service-orientierte Softwarearchitekturen auf Hochleistungsrechner-Plattformen, angriffssicher und mit Update- und Upgrade-Fähigkeit Overthe-Air, stehen bei vielen Herstellern auf der Roadmap. Die Herausforderung liegt in der Umsetzung: neues Denken, neue Strukturen und neue Prozesse sind gefordert. Organisationsstrukturen müssen daher angepasst werden, um Veränderungen einzuleiten. Hier ist Mut gefordert, um zum Beispiel durch vergrößerte Verantwortungsumfänge ein Gegengewicht zum tradierten Denken aufzubauen - bis hin zur Vorstandsebene.

Es gilt, Konsequenzen zu akzeptieren und zu investieren, und standardbasierte Plattformen zu entwickeln: Ziel ist die Entkopplung der Funktionsentwicklung von Fahrzeugprojekten - und damit auch die Notwendigkeit, die Entwicklung der Plattform so weit wie möglich von ihrem Ersteinsatz zu entkoppeln - zeitlich, organisatorisch und budgetseitig, wie das im Übrigen beispielsweise bei der Entwicklung neuer Motoren zur Risikominimierung schon seit Jahrzehnten gemacht wird.
Eigene, schlagkräftige Einheiten müssen aufbaut und organisatorische Freiräume geschaffen werden: Hierzu haben mehrere OEMs in den vergangene zwei Jahren Entwicklungszentren von Halbleiter- und Technologieherstellern übernommen, die von diesen aufgrund geänderter strategischer Schwerpunkte nicht mehr benötigt wurden. Als eigene organisatorische Einheiten, außerhalb der bestehenden Kern-Entwicklungsorganisation wird so ein mit kritischer Masse ausgestatteter „Veränderungs-Nukleus“ geschaffen. Dort können in einem nächsten Schritt - unter Einbindung von Partnern - auch neue kundenrelevante Funktionen in einer „Software Factory“ kontinuierlich entwickelt und über OTA-Updates verfügbar gemacht. Vorlage ist das „DevOps“-Modell, in dem die Entwickler auch extensive operationale Verantwortung für die Freigabe von Seriencode wahrnehmen.

Die Mannschaft mitnehmen. Ein klarer Migrationspfad für die bestehende Organisation ist notwendig, um den in aktuellen, klassischen Projekten arbeitenden Mitarbeitern klare Chancen und attraktive Perspektiven aufzuzeigen. Prozessuale und organisatorische Veränderungen sind aber nicht nur in der Entwicklung, sondern auch in Einkauf, Vertrieb, Produktion und Controlling notwendig, um softwarezentriert zu arbeiten.

Das vernetzte Fahrzeug wird somit zum „Handheld auf Rädern“ - und der klassische SOP zum „Release 1.0“. 